\title{
Acid Degradation of Erythromycin A and Erythromycin B
}

The recent isolation of 8,9 -anhydroerythronolide $B$ 6,9-hemiketal after treatment of erythronolide B under acidic conditions ${ }^{1}$, led us to an investigation of the acid degradation products of erythromycin A (1) and erythromycin B (2). A solution of erythromycin A (1) in glacial acetic acid was allowed to stand at room temperature for $2 \mathrm{~h}$ and worked up in a manner similar to that of STEPHENS and Conine 2 , to give, after recrystallization from carbon tetrachloride, a $72 \%$ yield of a compound which gave an elemental analysis in agreement with the empirical formula $\mathrm{C}_{37} \mathrm{H}_{65} \mathrm{NO}_{12}$. The compound had a melting point of $133-135^{\circ} ;[\alpha]_{D}^{55}-43^{\circ}$ (c, 1.19 in $\mathrm{MeOH}$ ); of these couplings suggested that the allylic protons were geminal. This then established that the vinyl methyl groups were at $\mathrm{C}-8$ and the allylic protons were at $\mathrm{C}-7$. This confirmed that 3 and 4 were 8,9 -anhydroerythromycin $A$ and $B$ 6,9-hemiketals, respectively.

The hydrolysis of $\mathbf{3}$ in dilute aqueous methanolic hydrochloric acid ${ }^{1}$ for $45 \mathrm{~min}$ afforded, after work-up and recrystallization from methylene chloride-hexanc, a $64 \%$ yield of 'anhydroerythromycin $A^{\prime}(5)^{4}, \operatorname{mp~} 130-140^{\circ}$, identical with a reference sample of 5 prepared according to the procedure of WILEY et al. ${ }^{4}$ from 1 by criteria of thin layer chromatography, IR- and NMR-spectral

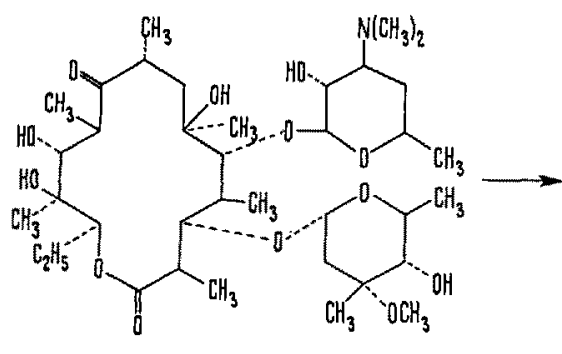

1

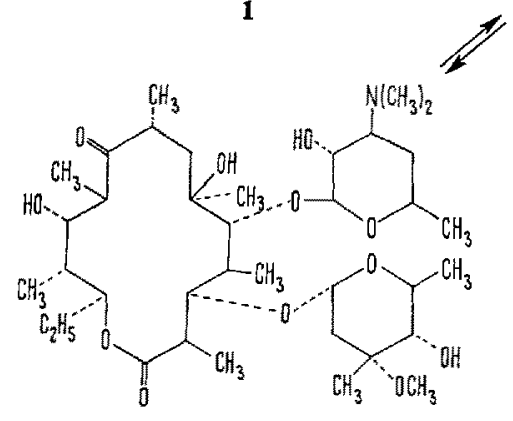

2

$\lambda_{\max }^{\mathrm{MeOH}} 209 \mathrm{~nm}(\varepsilon 6640) ; \tilde{\nu}_{\text {max }}^{\mathrm{CHCl}} \mathrm{Cl}_{3} 3620,3520-3550,1718 \mathrm{~cm}^{-1}$. Neither the analytical result nor the UV-absorption of this compound was compatible with the previously proposed 'hemiketal' structure ${ }^{2}$. The above physical constants strongly suggested that the product was an enol ether analogous to those obtained in the erythronolide $B$ series ${ }^{1,3}$. Consideration of the NMR spectral evidence presented below established the structure of this substance as 8,9-anhydroerythromycin A 6,9-hemiketal (3).

Treatment of erythromycin B (2) in acetic acid under the same conditions followed by recrystallization of the reaction product from acetone gave a $50 \%$ yield of 8,9-anhydroerythromycin B 6,9-hemiketal (4), $\mathrm{C}_{37} \mathrm{H}_{65} \mathrm{NO}_{11}, \operatorname{mp} 80-82^{\circ} ;[\alpha]_{\mathrm{D}}^{25}-33^{\circ}$ (c, 1.14 in $\mathrm{MeOH}$ ); $\lambda_{\text {max }}^{\mathrm{MeOH}} 209 \mathrm{~nm}(\varepsilon 7120) ; \tilde{\boldsymbol{v}}_{\text {max }}^{\mathrm{CHCl}_{\mathrm{s}}} 3612,3555,3450,1720 \mathrm{~cm}^{-1}$.

The NMR-spectra of both, 3 and 4 , like that of 8,9 anhydroerythronolide $B$ 6,9-hemiketal ${ }^{1}$, revealed the presence of single vinyl methyl resonances $(1.61 \mathrm{ppm}$ in the pyridine- $d_{5}$ solution spectra of both compounds at $110^{\circ}$ ) and the absence of vinyl proton resonances. The vinyl methyl resonances were broadened by unresolved allylic couplings (ca. $1.0 \mathrm{~Hz}$ ) with 2 ring protons, the chemical shifts of which $(2.85 \mathrm{ppm}$ and $2.07 \mathrm{ppm}$ for 3 ; 2.83 and $2.04 \mathrm{ppm}$ for 4 ) were determined by spin decoupling experiments. The resonances of the allylic protons of 3 and 4 appeared as $A B$ quartets $\left(J_{\mathrm{AB}}=15 \mathrm{~Hz}\right)$, the peaks of which were slightly broadened by allylic coupling to the vinyl methyl protons. The magnitudes

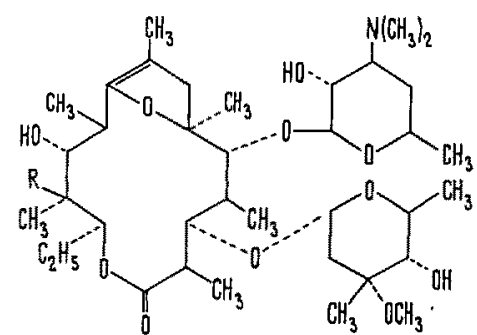

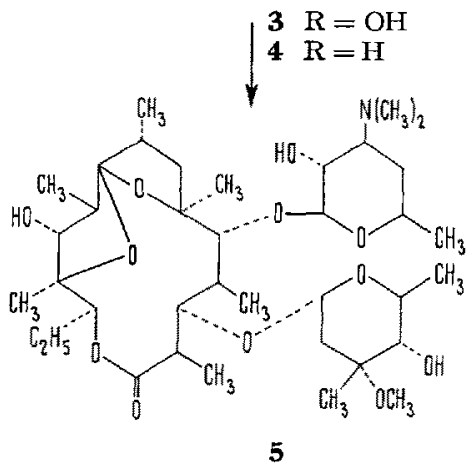

evidence. In contrast, acid hydrolysis of 4 under the same conditions furnished, after recrystallization from acetone, a $42 \%$ yield of erythromycin B (2), mp 200-203. Examination of molecular models indicated that only one side of the double bonds of the enol ethers 3 and 4 were readily accessible to an attacking reagent ${ }^{1}$. This observation was consistent with the formation of $\mathbf{5}$ and $\mathbf{2}$ (the crude reaction products were pure by thin layer chromatography) during the brief hydrolyses of $\mathbf{3}$ and $\mathbf{4}$, respectively.

Zusammenfassung. Es wird die Bildung der 8,9-Anhydroerythromycin A und B 6,9-Hemiketale aus den entsprechenden Erythromycinen mit Essigsäure bewiesen.

P. Kurath, P. H. Jones,

R. S. Egan and T. J. Perun

Scientific Divisions, Abbott Laboratories,

North Chicago (Illinois 60064, USA), 5 October 1970.

1 P. Kurath and R. S. Egan, Helv, chim. Acta, in press.

2 V.C. Stephens and J. W. Conine, Antibiotics A. 1958-1959, 346.

3 T. J. PERun, J. org. Chem. 32, 2324 (1967).

4 P. F. WILeY, K. Gerzon, E. H. FlyNN, M. V. Sigal JR., O. Weaver, U. C. Quarck, R. R. Chauvette and R. Monahan, J. Am. chem. Soc. 79, 6062 (1957). 